crosenati

\title{
Telemedicine in the diagnosis and treatment of sleep apnoea
}

\author{
Marie Bruyneel \\ Number 2 in the Series "Sleep Disordered Breathing" \\ Edited by Renata Riha and Maria Bonsignore
}

Affiliation: Dept of Pneumology, CHU Saint Pierre, Université Libre de Bruxelles, Brussels, Belgium.

Correspondence: Marie Bruyneel, Service de Pneumologie, Hôpital Saint Pierre, 322 rue Haute, 1000 Brussels, Belgium; E-mail: marie_bruyneeldstpierre-bru.be

@ERSpublications

Using telemedicine in obstructive sleep apnoea patients under continuous positive airway pressure therapy leads to reductions in nursing workload, early identification of problematic patients, and at least similar treatment adherence. http://ow.ly/dfL830nuBzD

Cite this article as: Bruyneel M. Telemedicine in the diagnosis and treatment of sleep apnoea. Eur Respir Rev 2019; 28: 180093 [https://doi.org/10.1183/16000617.0093-2018].

ABSTRACT Telemedicine (TM) is a current tool in the landscape of medicine. It helps to address public health challenges such as increases in chronic disease in an ageing society and the associated burden in healthcare costs. Sleep TM refers to patient data exchange with the purpose of enhancing disease management. Obstructive sleep apnoea (OSA) syndrome is a chronic disorder associated with a significant morbidity, mainly cardiometabolic, and mortality. Obtaining adequate compliance to continuous positive airway pressure (CPAP) remains the greatest challenge related to OSA treatment, and the adoption of TM to support OSA management makes sense. In addition, the prevalence of OSA is growing and OSA is associated with increased healthcare costs that could be streamlined by the application of TM. In OSA, multiple modalities of TM are utilised, such as telediagnostics, teleconsultation, teletherapy and telemonitoring of patients being treated with CPAP. In the present article, I aim to provide an overview of current practice and the recent developments in TM for OSA management. Concerns related to TM use will also be addressed.

\section{Introduction}

The use of telemedicine (TM) is growing worldwide [1]. Miniaturisation and the ubiquitous use of smartphones have opened new communication pathways between patients and caregivers, but have also contributed to a climate of "apomediation" where patients are constantly seeking information on the internet, profoundly modifying the bond of trust between doctor and patient [2].

TM is defined as the practice of medicine using electronic communications, information technology or other means between a licensee in one location and a patient in another location, with or without an intervening healthcare provider [3]. The scope of TM is broad such that the terminology is complex, as summarised in table 1.

Sleep TM refers to the exchange of patient data with the purpose of enhancing disease management. Data are transmitted by telephone or via the internet, through video and smartphone applications. Feedback to the patient is provided using the same methods.

Received: Oct 062018 | Accepted after revision: Jan 232019

Provenance: Submitted article, peer reviewed.

Previous articles in this series: No. 1: Masa JF, Pepin J-L, Borel J-C, et al. Obesity hypoventilation syndrome. Eur Respir Rev 2019; 28: 180097.

Copyright OERS 2019. ERR articles are open access and distributed under the terms of the Creative Commons Attribution Non-Commercial Licence 4.0. 


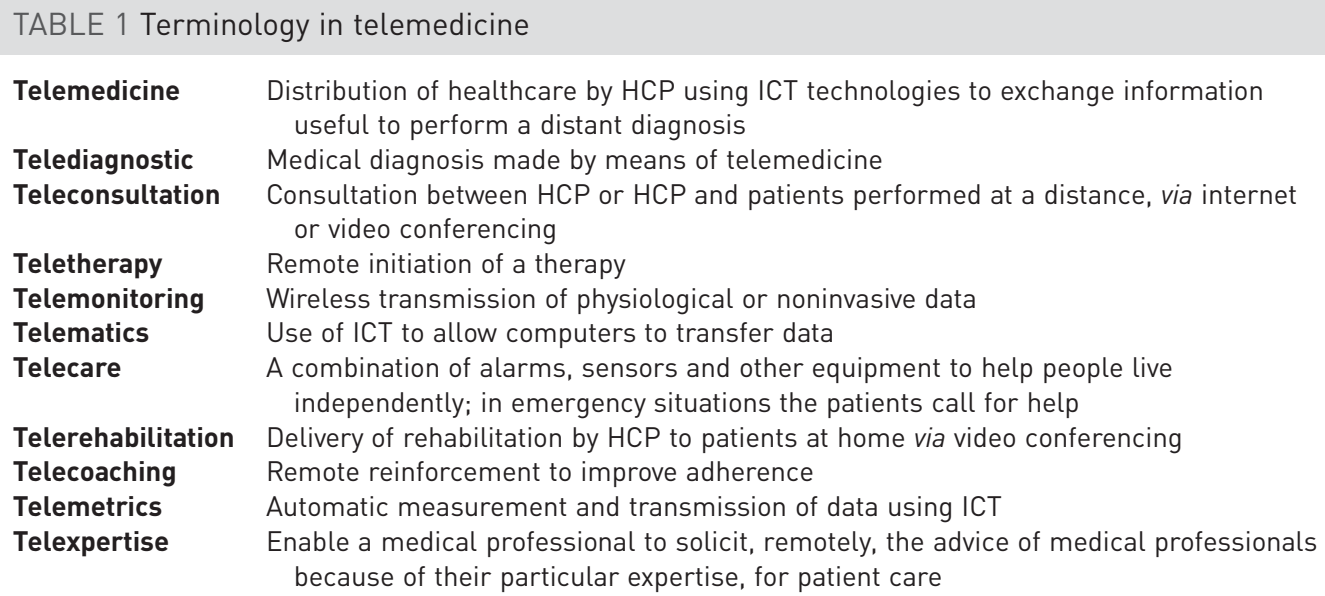

Telemedicine

Telediagnostic

Teleconsultation

Teletherapy

Telemonitoring

Telematics

Telecare

Telerehabilitation

Telecoaching

Telemetrics

Telexpertise

Distribution of healthcare by HCP using ICT technologies to exchange information useful to perform a distant diagnosis

Medical diagnosis made by means of telemedicine

Consultation between HCP or HCP and patients performed at a distance, via internet or video conferencing

Remote initiation of a therapy

Wireless transmission of physiological or noninvasive data

Use of ICT to allow computers to transfer data

A combination of alarms, sensors and other equipment to help people live independently; in emergency situations the patients call for help

Delivery of rehabilitation by HCP to patients at home via video conferencing

Remote reinforcement to improve adherence

Automatic measurement and transmission of data using ICT

Enable a medical professional to solicit, remotely, the advice of medical professionals because of their particular expertise, for patient care

Note that this is a non-exhaustive list. HCP: healthcare providers; ICT: information and communication technologies.

In the field of sleep disorders, TM can potentially help improve access to healthcare, reduce waiting times for medical visits or investigations, and increase adherence to treatment [4]. TM overcomes the problems of distance, traffic congestion and absence from work for medical visits. A recent position paper from the American Academy of Sleep Medicine (AASM) related to the use of TM in sleep disorders stresses that, "the practice of telemedicine should aim to promote a care model in which sleep specialists, patients, primary care providers, and other members of the healthcare team aim to improve the value of healthcare delivery in a coordinated fashion" [5]. However, despite the fact that TM can be used easily in a large array of sleep disorders, the majority of TM research papers are focused on obstructive sleep apnoea (OSA) treatment.

OSA is a chronic disorder associated with significant morbidity, mainly cardiometabolic, and mortality. Excessive daytime sleepiness is responsible for impaired quality of life (QoL) and neurocognitive performance in these patients [6,7]. Continuous positive airway pressure (CPAP) is the mainstay of treatment, improving QoL and reducing mortality [8]. Obtaining adequate compliance remains the greatest challenge related to OSA treatment, and TM makes sense in this setting. In addition, the prevalence of OSA is growing and is associated with increased healthcare costs that could be streamlined by the application of TM $[9,10]$. As shown in table $2, \mathrm{TM}$ can be utilised in all aspects of OSA patient management.

Although we have observed a constant increase in the routine use of telemonitoring by sleep centres [10], generalisation of the use of TM has been hampered by multiple barriers. In the present article, we aim to provide an overview of current practices and recent developments in the field of OSA management using TM.

\section{Telediagnostics in OSA}

\section{Telemonitored sleep recording}

The main goal of sleep TM is to obtain good quality sleep recordings outside the sleep lab. Home (or unattended) polygraphy or polysomnography (PSG) avoids the need for patients to face long waiting lists for an attended in-lab PSG [11]. PSG in the sleep lab is still the reference method for OSA diagnostics

\section{TABLE 2 Potential use of telemedicine in obstructive sleep apnoea patient management}

\section{Usual pathway}

Diagnostic

Consultation

CPAP education

CPAP titration

CPAP follow-up
Attended PSG and home PG

Face-to-face patient-physician consultation Face-to-face training

Sleep lab attended CPAP titration and home APAP titration

Face-to-face patient-physician consultation
Telemedicine pathway

Remotely attended PSG/PG

Patient-physician teleconsultation

Video conferencing training

Remotely attended CPAP titration

Telemonitoring, patient-physician teleconsultation, automated teledriven feedback, web-based supporting tools

CPAP: continuous positive airway pressure; APAP: automated CPAP; PSG: polysomnography; PG: polygraphy. 
[12] but, due to the growing number of patients suffering from OSA, we have observed a shift to the use of easier and less expensive diagnostic tools, such as polygraphy, that offer limited sleep studies. Type III polygraphy devices [13] that can measure airflow, respiratory effort and oximetry, exhibit wide variability in sensitivity and specificity, from $64 \%$ to $100 \%$ and from $41 \%$ to $100 \%$, respectively, depending on the brand and how it is used [14].

AASM has recently recommended the use of polygraphy, with a technically adequate device, for the diagnosis of OSA in uncomplicated adult patients presenting with signs and symptoms that indicate an increased risk of moderate-to-severe OSA [15].

There are still quality concerns regarding the use of home polygraphy devices, which have generally had a failure rate of $\sim 5-30 \%$ [16]. However, this has improved in more recent studies [17] and current failure rates for home PSG are generally $<8 \%$ [18]. Effort should be made to avoid failures and the need to repeat recordings.

TM has been used in the context of sleep recording for two purposes. The first is to make home polygraphy recordings quickly available for analysis, using TM for data transmission. This has been studied by Borsini et al. [19] in Buenos Aires where polygraphy was performed at home, but fitted by non-expert technicians. Raw data were sent by e-mail the following day. In this classical population of patients highly likely to suffer from OSA the failure rate was $4 \%$, and $12 \%$ needed an additional in-lab PSG. These positive results have allowed healthcare providers to enhance accessibility to sleep tests in a large country with few expert sleep centres [19].

The second context for the use of TM for sleep recording has been to ensure the quality of unattended polygraphy/PSG (performed at home or in a virtual hospital) by intermittent or continuous remote supervision of recording. The impact of real-time telematic transmission for unattended PSG was first tested by GaGnadoux et al. [20] in a prospective randomised crossover trial. 99 patients underwent one home PSG and one in-hospital unattended, but telemonitored, PSG (TM-PSG) on two consecutive nights. The TM-PSG was performed in the medical wards of two peripheral hospitals, with intermittent, real-time, remote control from the sleep technicians of the central sleep lab (every $30 \mathrm{~min}$ ). In case of loss of signal, the technicians instructed the nursing staff at the two hospitals on how to replace the electrodes. A technical intervention was required for 13 TM-PSG, but nurses could only solve nine problems. Finally, the TM-PSG failure rate was $11 \%$ versus $23 \%$ for home PSG.

In our lab, we have conducted two studies to assess real-time remote supervision of home or unattended PSG $[21,22]$. In the first pilot study, we assessed 21 patients likely to suffer from OSA at home. The Sleepbox tool (Sleepbox ${ }^{\oplus}$, Medatec, Belgium) was added to the polysomnograph in order to transmit recordings to the technicians at the sleep lab in real time. They performed remote monitoring of the home PSG every hour. In case of sensor loss, the technician was able to call the patient through Skype or via the microphone of the Sleepbox to ask the patient to replace the sensors correctly. The results of this pilot study were interesting but highlighted several technical problems, especially with Skype. Overall, 90\% of the recordings were graded excellent in terms of quality, but among the $10 \%$ of failed PSG recordings, one was due to the polysomnograph (battery failure), such that only one was attributable to a poor quality recording. Two Skype interventions were required for sensor losses, resulting in readjustment of defective probes. The second study was performed in a very different setting. In this study, we performed real-time monitoring of unattended PSG in an acute coronary care ward in 27 patients hospitalised for acute coronary syndrome, with the purpose of screening for OSA. Unattended PSG was remotely and continuously supervised from the sleep lab, which was located in another building of the same hospital. As in the study of Gagnadoux et al. [20], the sleep technicians instructed the nursing staff in the acute coronary care ward on how to replace the electrodes when faulty signals were detected. We obtained very good results with $100 \%$ interpretable sleep recordings and $89 \%$ graded as excellent. Once more, we had to deal with technical problems related to the $3 \mathrm{G}$ network connection, exhibiting why Sleepbox was only efficient in $78 \%$ of patients. However, the 10 successful interventions did effectively increase the global quality of the PSG recordings.

An additional study of TM sleep recording was conducted in Spain by CoMA-DEL-CorRAL et al. [23]. A "Virtual Sleep Unit" was created at a distance of $80 \mathrm{~km}$ from the central sleep lab. Real-time continuously supervised telemonitored polygraphy was performed. Placement of polygraphy was done by the local nursing staff under remote supervision from the central sleep lab in patients likely to suffer from OSA. Supervision also included continuous video monitoring via a webcam. No telemonitored polygraphy failures were observed, but data transmission failed for $2.5 \%$ of the recordings.

These four pilot studies have confirmed the feasibility and the potential interest in telemonitored sleep recording, which is not routinely applied in current practice. 
Teleconsultation following OSA diagnosis

TM can be used as a tool to facilitate consultations to explain diagnosis and therapy to recently diagnosed OSA patients. In this setting, TM can provide real-time clinician-patient interactions, often via the internet or video conferencing.

\section{Teleconsultation}

COMA-DEL-Corral et al. [23] applied teleconsultation in patients with confirmed OSA. After telemonitored polygraphy, patients were randomised to receive either a face-to-face consultation or a teleconsultation to receive the results of their sleep study. The teleconsultation was made via video conferencing. It was followed by a home trial with an automated positive airway pressure (APAP) device for the 16 patients requiring CPAP, and the data were telematically transmitted for 2 nights. At 6 months, in this very small group of patients, adherence was not different between the groups: $85 \%$ for the face-to-face consultation and $75 \%$ for the teleconsultation group.

\section{CPAP education}

In a study of CPAP education, ISETTA et al. [24] included 40 OSA-naïve patients and scheduled them for CPAP training either by video conference (20 patients) or usual face-to-face practice (20 patients). After the training, patients answered questionnaires anonymously about what they had learned. The results showed that both knowledge and practical skills (e.g. mask and headgear placement and leak avoidance) related to OSA and CPAP therapy were equivalent between the groups ( $94 \%$ correct answers in the video conference group versus 92\%) [24]. Thus, teleconsultation is feasible and leads to adequate knowledge when used for CPAP training.

\section{Telemonitored remote CPAP treatment initiation}

Home APAP titration, controlled by polygraphy, is a valuable alternative to in-lab attended titration and results in similar clinical outcomes in terms of adherence, sleepiness improvement and QoL [25-27]. Treatment adjustments are performed a posteriori, including the shift from APAP to fixed CPAP device and mask adaptations. However, in real-life settings, clinicians can be confronted with high failure rates for home APAP titration, up to $20 \%$ in one Canadian experience [17], leaving plenty of room for improvement.

Disappointingly, only one study has tested remote-attended CPAP titration at home. DellaCA et al. [28] studied 20 severe OSA patients exposed to CPAP for the first time. A telemetric unit was coupled to the CPAP device. Using GPRS mobile phone network, the technical team from the sleep lab was able to remotely control CPAP parameters (flow, pressure and leaks) and to adapt CPAP pressure. An attended CPAP titration PSG was performed 1 week later in the sleep lab, leading to the same pressure settings: $9.15 \mathrm{cmH}_{2} \mathrm{O}$ at home versus $9.2 \mathrm{cmH}_{2} \mathrm{O}$ in the sleep lab.

This interesting exploratory study, which allowed sleep technicians to avoid potential failures of APAP trials at home, has not yet been followed by larger scale trials.

\section{Managing CPAP treated patients with TM}

When treating OSA patients with CPAP, the challenge of obtaining adequate adherence is clearly an essential feature. Adherence is defined as use during at least $4 \mathrm{~h} \cdot$ night $^{-1}$ and for $>70 \%$ of nights [29]. However, on an individual basis, greater adherence is required as the effects of CPAP grow with increased use. A linear relationship between CPAP use and subjective/objective sleepiness, functional outcomes assessed by sleep questionnaire, and improvement in memory has been demonstrated when CPAP was used for $>6 \mathrm{~h} \cdot$ night $^{-1}$ in comparison with $<2 \mathrm{~h} \cdot$ night $^{-1}$ [30]. Longer CPAP use also achieves greater reductions in blood pressure and sleepiness [31].

In a cohort of 3100 CPAP treated patients, BoulOUKAKI et al. [32] randomised patients to intensive versus standard interventions and confirmed the positive effects of greater CPAP use (6.9 versus $5.2 \mathrm{~h} \cdot$ night $^{-1}$ ) on cardiovascular outcomes, highlighting that regular use of $5-6 \mathrm{~h} \cdot$ night $^{-1}$ is required.

Predictive factors of low adherence have been identified in several studies. Low CPAP use at 1 month and side-effects at 1 month are predictors of low 12-month CPAP adherence [33]. Oro-nasal masks, depression and low effective pressure are also predictors of poor adherence [34]. Indeed, consistent and inconsistent users can be distinguished within the first week [35,36], and adherence at 1 month is associated with adherence at 3-6 months [29, 37]. As intensive early intervention could improve long-term CPAP adherence; TM supporting strategies implemented early after CPAP initiation therapy could be a crucial element to improving patient care. 
The first TM studies were designed using automated TM tools such as interactive websites [38], interactive telephone-based voice response systems [39], or daily internet-based informational support and feedback systems (a combination of branching questions, symptom management, health behaviour and knowledge) to support patients, independently of CPAP device reported data [40]. Since these first attempts, which reported conflicting results on CPAP adherence, CPAP devices have evolved and now offer, on a daily basis, accurate data on adherence, compliance, mask leaks, residual apnoeas and CPAP pressure. This technological progress has changed the landscape of TM intervention for CPAP users [41].

\section{Telemonitoring of adherence, compliance, mask leaks, residual apnoeas and CPAP pressure}

Currently, the majority of CPAP devices on the market have wireless built-in connectivity, such that they have the ability to transfer technical data on a daily basis via a central secured data centre (a cloud) to sleep labs or home care providers $[41,42]$. It is also possible to remotely change the settings of the device [43]. The usefulness of telemonitoring for caregivers/patients has been reported in several randomised controlled trials (RCT), which are summarised in table 3.

Improved adherence has been shown in four out of seven studies [38, 44, 48, 49]. When assessed, patient acceptance of telemonitoring and satisfaction rates were also positive. Telemonitoring is often perceived as a means of reassurance for the patients [10]. The interest in telemonitoring has evolved from adherence focused purposes for other aims, such as nurse timesaving and amelioration of care for difficult-to treat patients.

Indeed, in an RCT from HoET et al. [49], telemonitoring was applied to CPAP treated patients with the goal of assessing the impact of telemonitoring on the delay to the first technical intervention after CPAP initiation. 46 patients were randomised to usual care or telemonitoring. A total of $65 \%$ of patients in the usual care group and $78 \%$ in the telemonitoring group required treatment adaptation early in the course of CPAP therapy. Telemonitoring helped sleep technicians to act proactively soon after the beginning of the treatment, as interventions were triggered by the telemonitoring for $39 \%$ of patients. The authors were able to show a reduction in the delay to first intervention of 18 days in the telemonitoring group, and this closer follow-up led to better 3-month adherence (5.7 versus $4.2 \mathrm{~h} \cdot \mathrm{night}^{-1}$ ).

After treatment initiation, telemonitoring can be used to rapidly identify two categories of patients: those who quickly adapted well and those with problems (e.g. acceptance, leaks, adherence, mask discomfort, nasal/mouth dryness) who need more support/intervention. For patients belonging to the first category,

TABLE 3 Results of the randomised studies comparing telemedicine (TM) follow-up versus usual care for continuous positive airway pressure (CPAP) patients

\begin{tabular}{|c|c|c|c|c|c|}
\hline $\begin{array}{l}\text { First author } \\
\text { [ref.] }\end{array}$ & Patients $\mathbf{n}$ & $A H I$ events $\cdot h^{-1}$ & TM application & $\begin{array}{c}\text { Adherence TM versus } \\
\text { usual care }\end{array}$ & Patient satisfaction \\
\hline StePNOWSKY [38] & 45 & $>15$ & $\begin{array}{l}\text { Interactive website with own } \\
\text { CPAP data and guide for } \\
\text { troubleshooting }\end{array}$ & $\begin{array}{c}2 \text { months: } 4.1 \text { versus } \\
3.4 \text { h.night }{ }^{-1} \text { (statistically } \\
\text { significant) }\end{array}$ & $\begin{array}{l}\text { No concerns of being } \\
\text { remotely observed }\end{array}$ \\
\hline Fox [44] & 75 & $>15 ;$ mean: 42 & Feedback by phone & $\begin{array}{c}3 \text { months: } 3.2 \text { versus } \\
1.7 \mathrm{~h} \cdot \text { night }^{-1} \text { (statistically } \\
\text { significant) }\end{array}$ & NA \\
\hline Anttalainen [46] ${ }^{\#}$ & 111 & Mean: 34 & Nurse adjustment phone/visits & 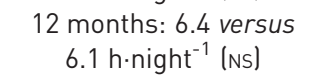 & NA \\
\hline Munafo [47] & 132 & $\begin{array}{l}\text { Mean: } 34 \text { (TM), } \\
27 \text { (usual care) }\end{array}$ & $\begin{array}{l}\text { Multimedia approach to contact } \\
\text { patient about their CPAP use }\end{array}$ & $\begin{array}{l}1 \text { month: } 5.1 \text { versus } \\
4.7 \mathrm{~h} \cdot \mathrm{night}^{-1} \text { (NS) }\end{array}$ & $\begin{array}{l}\text { Very good acceptance of } \\
\text { the TM programme }\end{array}$ \\
\hline FrASNELLI $[48]^{\top 1}$ & 223 & $\begin{array}{l}\text { Median: } 37 \\
\text { (TM), } \\
40 \text { (usual care) }\end{array}$ & $\begin{array}{l}\text { Pneumologist adjustment by } \\
\text { phone }\end{array}$ & $\begin{array}{c}1 \text { month: } 5.3 \text { versus } \\
4.6 \text { h.night }{ }^{-1} \text { (statistically } \\
\text { significant) }\end{array}$ & $\begin{array}{c}\text { Overall satisfaction better } \\
\text { in usual care group; privacy } \\
\text { concerns }\end{array}$ \\
\hline TuRINo [50] & 100 & $>15$ & $\begin{array}{l}\text { Pneumologist adjustment by } \\
\text { phone }\end{array}$ & $\begin{array}{l}3 \text { months: } 5.1 \text { versus } \\
4.9{\mathrm{~h} \cdot \mathrm{night}^{-1}}^{-1} \text { (NS) }\end{array}$ & $\begin{array}{l}\text { Overall satisfaction better } \\
\text { in usual care group; privacy } \\
\text { concerns }\end{array}$ \\
\hline
\end{tabular}

AHI: apnoea/hypopnoea index; NS: not statistically significant; NA: not assessed. ${ }^{\#}$ : partially randomised; ${ }^{\text {ๆ: }}$ patients selected at random. 
face-to-face consultations could be spaced, leaving more time for the nursing/technical staff to give care to the problematic patients. AntTALAinen et al. [46] demonstrated a saving of $19 \mathrm{~min}$ in nursing time between telemonitoring patients and the usual care group, in 111 patients.

There is sufficient evidence to support the routine use of telemonitoring in sleep units including: the non-inferiority of telemonitoring compared to usual care for adherence; the decrease in nursing workload; the proactive aspects of technical interventions; and the early identification of problematic patients.

\section{Teleconsultation for CPAP treated patients}

The aim of teleconsultation is patient counselling with the purpose of reinforcing and supporting CPAP treatment goals. In a recent study from ISETTA et al. [24], 50 patients with OSA were enrolled to attend a sleep laboratory for CPAP follow-up visits. These patients underwent a teleconsultation with the physician and were asked to evaluate the teleconsultation anonymously afterwards. More than $95 \%$ of the interviewed patients were satisfied with the teleconsultation, and $66 \%$ responded that teleconsultations could replace $50-100 \%$ of their CPAP follow-up visits.

PARIKH et al. [51] compared teleconsultation delivered by video conferencing with face-to-face consultation for CPAP follow-up in 90 patients. The proportion of adherent patients and levels of patient satisfaction were not different between the two groups [51].

In a recent review from MURPHIE et al. [52], the authors performed a systematic review on the role of remote teleconsultation associated with telemonitoring for OSA patient follow-up. Four RCT studies and one controlled clinical trial (269 patients) were included in the analysis. Results regarding adherence were mixed, with two studies showing similar adherence to CPAP $[23,40]$ and three others, of smaller size, demonstrating slight improvements $[44,38,53]$. Patient satisfaction with teleconsultation was similar to that for face-to-face consultation. The author's conclusion was that these studies (including four with a moderate-to-high risk of bias) do not provide definitive evidence of the effectiveness (in terms of adherence and symptom control) of teleconsultation/telemonitoring in CPAP users; however, there was no suggestion of any harm. They stressed the need for adequately powered trials at low risk of bias to establish whether the combination of remote consultation and real-time telemonitoring is a clinically viable, acceptable and cost-effective option for OSA patients using CPAP therapy.

\section{Automated teledriven feedback for CPAP treated patients}

In the area of automated feedback, one study has assessed the impact of direct access to daily CPAP device parameters for patients. KUNA et al. [25] randomised 138 recently diagnosed OSA patients requiring CPAP to usual care, usual care with access to CPAP usage, or usual care with access to CPAP usage and a financial incentive. After 3 months, mean adherence was 4.8 and $5 \mathrm{~h} \cdot$ night $^{-1}$ in the intervention groups versus $3.8 \mathrm{~h} \cdot$ night $^{-1}$ for usual care $(\mathrm{p}<0.0001)$. Web access and direct daily feedback seems to act positively on adherence. Interestingly, patients frequently consulted their own data during the first week of treatment but then interest in their own data decreased rapidly. More CPAP data consultation was associated with better CPAP adherence.

More recently, in the Tele-OSA trial, HwANG et al. [54] assessed the use of TM web-based OSA education (Tel-Ed) and CPAP telemonitoring with automated patient feedback (Tel-TM) on adherence. A total of 1455 patients were randomised to four arms to receive usual care, usual care+Tel-Ed, usual care+Tel-TM or usual care+Tel-Ed+Tel-TM (Tel-both). The use of CPAP telemonitoring with automated patient feedback messaging improved 90-day adherence in patients with OSA. However, a 1-year follow-up analysis was performed and showed that adherence decreased 3 months after the end of the feedback messaging, matching the rate in the usual care arm but not in patients where messaging continued, suggesting the need for continuous support in these patients. TM web-based education added to usual care did not significantly improve CPAP adherence but did increase clinic attendance for OSA evaluation by $10 \%$.

Using automated feedback seems interesting, at least in the beginning of treatment, but it is clear that a certain degree of weariness can be induced by the system.

\section{Patient support tools}

Several support tools, in the form of websites and/or apps, have been developed to help patients with CPAP therapy. STEPNOWSKY et al. [55] randomised CPAP users to usual care or MyCPAP (an interactive website that includes CPAP data, graphs and a troubleshooting guide) to measure the impact on adherence, internet use and satisfaction. Adherence was improved at 2 months in the MyCPAP group (3.4 versus $2.3 \mathrm{~h} \cdot$ night $^{-1}$ ), and internet use to seek OSA information also increased from $38 \%$ to $62 \%$ at 4 months. Skills obtained from MyCPAP were considered to be good for $88-94 \%$ of the patients. The majority were not concerned with privacy issues. 
At the 2018 European Respiratory Society International Congress, Engelman et al. [56] presented a retrospective study (data from Philips) comparing CPAP use in an "old fashioned" OSA cohort versus a "new feature" OSA cohort, including remote monitoring, device display and a patient support phone app. In the 817 included patients, the implementation of multiple telemedicine supporting tools resulted in an increase in daily CPAP use of $1.1 \mathrm{~h} \cdot$ night $^{-1}$ during the first 12 weeks of CPAP therapy.

A retrospective study assessed the impact of using a telemonitoring tool (pro-active care, AirView; Resmed Inc, San Diego, CA, USA) versus telemonitoring plus a patient engagement tool (AirView+myAir; Resmed) on termination rates. Use was $\geqslant 4 \mathrm{~h} \cdot$ night $^{-1}$ in $77 \%$ of the AirView group versus $63 \%$ in the proactive care group $(\mathrm{p}<0.001)$. Therapy termination rates were also lower in the patient engagement group [57]. These results were confirmed in a much larger cohort (128037 patients) where adherence was $5.9 \mathrm{~h} \cdot$ night $^{-1}$ in the AirView+myAir group versus $4.9 \mathrm{~h} \cdot$ night $^{-1}$ in the matched usual care group $(\mathrm{p}<0.0001)$ [58].

In a RCT, MENDELSON et al. [59] studied the use of an app to provide lifestyle counselling (diet/physical activity) and CPAP use support in 107 patients. Disappointingly, compared to the usual care arm, the app did not positively influence CPAP adherence, blood pressure measurements or physical activity.

The use of supporting tools generally results in better adherence. However, it is not sufficient to change lifestyle and behaviours.

\section{Discussion}

As we have discussed in this article, despite a lack of high-quality large randomised data, interest in the use of TM in OSA is clearly established, with the most evidence available for the use of telemonitoring, teleconsultation for treatment follow-up, and web tool support. As with any technological evolution, TM offers hope for improvement of patient care that is tempered by concerns about the potentially worrying aspects of this technique, including ethics, data ownership, privacy, billing, storage, and misuse of large databases [60]. In addition, the media often reports medical data breaches related to cybercriminal hacking [61]. How can physicians manage their patient-physician virtual relationships? How will physicians deal with this additional arrival of data from patient's homes?

Issues regarding the security and privacy of TM must be addressed by parties providing healthcare, e.g. governments, scientific organisations, hospitals and homecare provider companies [10]. Work in this area is in progress. For example, France has recently adopted a ministerial decree for the 2018 social security financing law approving the deployment of telemedicine both for doctor-patient consultations (teleconsultation) and "telexpertise" (between health professionals) [62].

Implementation of TM in sleep units requires important resources and a lot of time. On a regular basis sleep lab teams have to schedule a review of telemonitoring pre-established alarms in all CPAP treated patients. This implies profound changes in management for physicians and caregivers. Apart from planning adaptation and modification of patient-physician relationships, the question of responsibility is important. Usually, patients are reviewed at the consultation soon after CPAP initiation and then regularly, in order to assess/adapt treatment and solve problems. In the case of telemonitoring routine use, physicians can be technically aware of lack of compliance before the scheduled visit. What about a physician's responsibility if the patient has a car accident between the moment of detection of non-compliance and the visit? Or if the crash occurs between two moments of virtual review because of CPAP use interruption? Do we have to alert the patient immediately if non-compliance is detected? In sleep labs treating an important number of patients it seems unrealistic to check alerts and contact patients on a daily basis, but in case of a problem we could be blamed because we had to be theoretically informed of the situation.

The issue of cost-effectiveness related to TM use also remains crucial, despite decreases in the cost of information and communication technologies. The first cost analysis was performed in 2001, when the costs of information and communication technologies were higher. In a study that compared the costs of TM-PSG and home PSG for OSA diagnosis, the authors concluded that although TM was more effective (half the number of failures) it was also very expensive (\$244 versus \$153 for home PSG) [63].

More recently, two research teams have assessed the cost-effectiveness of TM follow-up in CPAP treated patients. In the first study, 139 CPAP patients were randomised to TM follow-up (telemonitoring and teleconsultation) or usual care for 6 months. TM was more cost-effective: despite more visits costs were lower and no significant differences in effectiveness were observed [45]. In the second study [50], in 100 CPAP patients randomised to telemonitoring or usual care for 3 months, the authors observed that telemonitoring was less expensive than standard management $(€ 124$ versus $€ 171 ; \mathrm{p}=0.022)$ and was cost-effective, but was associated with lower patient satisfaction. These two studies support the cost-effectiveness of TM for CPAP treated patients but need to be confirmed in larger series. 
Another concern is related to patients' perceptions of telemonitoring. In a recent study from TuRINo et al. [50], patients were not worried about being remotely observed through telemonitoring systems, but in another study of patient acceptance of telemonitoring, despite the fact that the majority (78\%) of the 160 studied patients expressed a favourable attitude toward telemonitoring, $40 \%$ consider this device intrusive [64].

Dehumanisation and depersonalisation of care can be poorly perceived by patients (e.g. telephone-based programmes and automatic e-mails) [65]. Specific communication skills that apply to the use of TM technologies should be learned by nurses and physicians.

The question of the qualifications of the caregiver giving patient feedback has also been debated. As the capacity of sleep centres is limited, a lot of studies have assessed OSA management, from diagnosis to CPAP treatment follow-up, by nurses and primary care physicians resulting in similar clinical outcomes [66]. However, in my opinion, even if the majority of OSA patient management could be shifted into the hands of non-sleep specialists, careful step-by-step algorithms should be implemented, provided by the sleep lab to avoid dangerous drifts in care such as lowering the quality of care, missing an OSA diagnosis in some patients, missing associated sleep disorders, and forgetting to offer other treatments besides CPAP for OSA. We have to keep in mind the study of PARTHASARATHy et al. [67] that demonstrated better global OSA patient management from accredited sleep centres and certified physicians. In practice, routine telemonitoring use has the potential to mask some aspects of care by relying excessively on technical parameters, forgetting the clinical picture. This could result in a decrease in medical quality, missing the fact, for example, that monitoring CPAP use, leak levels, and residual apnoeas can be satisfying, but in a patient still complaining of residual excessive sleepiness or comorbid insomnia it is not the whole picture $[68,69]$.

\section{Conclusion}

Telemedicine is a current tool in the landscape of medicine. It helps to address public health challenges such as increases in chronic disease in an ageing society and the associated burden in healthcare costs.

Healthcare organisation is undergoing many changes through the implementation of telemedicine and technology-based care. TM is going to change the patient-physician relationship and can simplify some aspects of diagnosis and care. However, TM carries an inherent risk of over reliance on technology and dehumanisation of care.

Based on the current literature, the use of TM in sleep medicine for OSA patient management seems to make sense. Recent studies have confirmed the cost-effectiveness of TM but this important issue should be addressed in future large-scale trials.

Acknowledgements: I would like to acknowledge the contribution of a medical writer, Sandy Field (Field Scientific, Lewisburg, PA, USA), in the preparation of this manuscript.

Conflict of interest: M. Bruyneel has received lecture fees from Chiesi, Novartis and Philips, travel fees from GSK, Chiesi, Novartis, Boehringer Ingelheim and AstraZeneca, and fees for educational presentations from Linde and Visisol, outside the submitted work.

\section{References}

Bruyneel M. Technical developments and clinical use of telemedicine in sleep medicine. J Clin Med 2016; 5.

2 Eysenbach G. From intermediation to disintermediation and apomediation: new models for consumers to access and assess the credibility of health information in the age of Web2.0. Stud Health Technol Inform 2007; 129: $162-166$.

3 Venkateshiah SB, Hoque R, Collop N. Legal aspects of sleep medicine in the 21st century. Chest 2018; 154: 691-698.

4 Kelly JM, Strecker RE, Bianchi MT. Recent developments in home sleep-monitoring devices. ISRN Neurol 2012: 768-794.

5 Singh J, Badr MS, Diebert W, et al. American Academy of Sleep Medicine (AASM) Position Paper for the Use of Telemedicine for the Diagnosis and Treatment of Sleep Disorders. J Clin Sleep Med 2015; 11: 1187-1198.

6 Yaggi HK, Concato J, Kernan WN, et al. Obstructive sleep apnea as a risk factor for stroke and death. $N$ Engl J Med 2005; 353: 2034-2041.

7 Engleman HM, Martin SE, Douglas NJ. Compliance with CPAP therapy in patients with the sleep apnoea/ hypopnoea syndrome. Thorax 1994; 49: 263-266.

8 Engleman HM, Kingshott RN, Wraith PK, et al. Randomized placebo-controlled crossover trial of continuous positive airway pressure for mild sleep apnea/hypopnea syndrome. Am J Respir Crit Care Med 1999; 159: 461-467.

9 Heinzer R, Vat S, Marques-Vidal P, et al. Prevalence of sleep-disordered breathing in the general population: the HypnoLaus study. Lancet Respir Med 2016; 3: 310-318.

10 Pepin JL, Tamisier R, Hwang D, et al. Does remote monitoring change OSA management and CPAP adherence? Respirology 2017; 22: 1508-1517.

11 Flemons WW, Douglas NJ, Kuna ST, et al. Access to diagnosis and treatment of patients with suspected sleep apnea. Am J Respir Crit Care Med 2004; 169: 668-672. 
12 Standards of Practice Committee of the American Sleep Disorders Association. Practice parameters for the use of portable recording in the assessment of obstructive sleep apnea. Sleep 1994; 26: 907-913.

13 Kushida CA, Littner MR, Morgenthaler T, et al. Practice parameters for the indications for polysomnography and related procedures: an update for 2005. Sleep 2005; 28: 499-521.

14 Qaseem A, Dallas P, Owens DK, et al. Diagnosis of obstructive sleep apnea in adults: a clinical practice guideline from the American College of Physicians. Ann Intern Med 2014; 161: 210-220.

15 Kapur VK, Auckley DH, Chowdhuri S, et al. Clinical Practice Guideline for Diagnostic Testing for Adult Obstructive Sleep Apnea: an American Academy of Sleep Medicine Clinical Practice Guideline. J Clin Sleep Med 2017; 13: 479-504.

16 Bruyneel M, Ninane V. Unattended home-based polysomnography for sleep disordered breathing: current concepts and perspectives. Sleep Med Rev 2014; 18: 341-347.

17 Stewart SA, Skomro R, Reid J, et al. Improvement in obstructive sleep apnea diagnosis and management wait times: a retrospective analysis of home management pathway for obstructive sleep apnea. Can Respir J 2015; 22: $167-710$

18 Bruyneel M, Libert W, Ameye L, et al. Comparison between home and hospital set-up for unattended home-based polysomnography: a prospective randomized study. Sleep Med 2015; 16: 1434-1438.

19 Borsini E, Blanco M, Bosio M, et al. "Diagnosis of sleep apnea in network" respiratory polygraphy as a decentralization strategy. Sleep Sci 2016; 9: 244-248.

20 Gagnadoux F, Pelletier-Fleury N, Philippe C, et al. Home unattended versus hospital telemonitored polysomnography in suspected obstructive sleep apnea syndrome: a randomized crossover trial. Chest 2002; 121: 753-758.

21 Bruyneel M, Van den Broecke S, Libert W, et al. Real-time attended home-polysomnography with telematic data transmission. Int J Med Inform 2013; 82: 696-701.

22 Van den Broecke S, Jobard O, Montalescot G, et al. Very early screening for sleep-disordered breathing in acute coronary syndrome in patients without acute heart failure. Sleep Med 2014; 15: 1539-1546.

23 Coma-Del-Corral MJ, Alonso-Alvarez ML, Allende M, et al. Reliability of telemedicine in the diagnosis and treatment of sleep apnea syndrome. Telemed J E Health 2013; 19: 7-12.

24 Isetta $\mathrm{V}$, Leon $\mathrm{C}$, Torres $\mathrm{M}$, et al. Telemedicine-based approach for obstructive sleep apnea management: building evidence. Interact J Med Res 2014; 3: e6.

25 Kuna ST, Gurubhagavatula I, Maislin G, et al. Noninferiority of functional outcome in ambulatory management of obstructive sleep apnea. Am J Respir Crit Care Med 2011; 183: 1238-1244.

26 Andreu AL, Chiner E, Sancho-Chust JN, et al. Effect of an ambulatory diagnostic and treatment programme in patients with sleep apnoea. Eur Respir J 2012; 39: 305-312.

27 Skomro RP, Gjevre J, Reid J, et al. Outcomes of home-based diagnosis and treatment of obstructive sleep apnea. Chest 2010; 138: 257-263.

28 Dellaca R, Montserrat JM, Govoni L, et al. Telemetric CPAP titration at home in patients with sleep apnea-hypopnea syndrome. Sleep Med 2011; 12: 153-157.

29 Kribbs NB, Pack AI, Kline LR, et al. Effects of one night without nasal CPAP treatment on sleep and sleepiness in patients with obstructive sleep apnea. Am Rev Respir Dis 1993; 147: 1162-1168.

30 Weaver TE, Maislin G, Dinges DF, et al. Relationship between hours of CPAP use and achieving normal levels of sleepiness and daytime functioning. Sleep 2007; 30: 711-719.

31 Barbe F, Duran-Cantolla J, Capote F, et al. Long-term effect of continuous positive airway pressure in hypertensive patients with sleep apnea. Am J Respir Crit Care Med 2010; 181: 718-726.

32 Bouloukaki I, Giannadaki K, Mermigkis C, et al. Intensive versus standard follow-up to improve continuous positive airway pressure compliance. Eur Respir J 2014; 44: 1262-1274.

33 Chai-Coetzer CL, Luo YM, Antic NA, et al. Predictors of long-term adherence to continuous positive airway pressure therapy in patients with obstructive sleep apnea and cardiovascular disease in the SAVE study. Sleep 2013; 36: 1929-1937.

34 Borel JC, Tamisier R, Dias-Domingos S, et al. Type of mask may impact on continuous positive airway pressure adherence in apneic patients. PLoS One 2013; 8: e64382.

35 Weaver TE, Kribbs NB, Pack AI, et al. Night-to-night variability in CPAP use over the first three months of treatment. Sleep 1997; 20: 278-283.

36 Aloia MS, Arnedt JT, Stanchina M, et al. How early in treatment is PAP adherence established? Revisiting night-to-night variability. Behav Sleep Med 2007; 5: 229-240.

37 Reeves-Hoche MK, Meck R, Zwillich CW. Nasal CPAP: an objective evaluation of patient compliance. Am J Respir Crit Care Med 1994; 149: 149-154.

38 Stepnowsky CJ, Palau JJ, Marler MR, et al. Pilot randomized trial of the effect of wireless telemonitoring on compliance and treatment efficacy in obstructive sleep apnea. J Med Internet Res 2007; 9: e14.

39 Sparrow D, Aloia M, Demolles DA, et al. A telemedicine intervention to improve adherence to continuous positive airway pressure: a randomised controlled trial. Thorax 2010; 65: 1061-1066.

40 Taylor Y, Eliasson A, Andrada T, et al. The role of telemedicine in CPAP compliance for patients with obstructive sleep apnea syndrome. Sleep Breath 2006; 10: 132-138.

41 Hwang D. Monitoring progress and adherence with positive airway pressure therapy for obstructive sleep apnea: the roles of telemedicine and mobile health applications. Sleep Med Clin 2016; 11: 161-171.

42 Zia S, Fields BG. Sleep telemedicine: an emerging field's latest frontier. Chest 2016; 149: 1556-1565.

43 Verbraecken J. Telemedicine applications in sleep disordered breathing: thinking out of the box. Sleep Med Clin 2016; 11: 445-459.

44 Fox N, Hirsch-Allen AJ, Goodfellow E, et al. The impact of a telemedicine monitoring system on positive airway pressure adherence in patients with obstructive sleep apnea: a randomized controlled trial. Sleep 2012; 35: $477-481$.

45 Isetta V, Negrin MA, Monasterio C, et al. A Bayesian cost-effectiveness analysis of a telemedicine-based strategy for the management of sleep apnoea: a multicentre randomised controlled trial. Thorax 2015; 70: 1054-1561.

46 Anttalainen U, Melkko S, Hakko S, et al. Telemonitoring of CPAP therapy may save nursing time. Sleep Breath 2016; 20: 1209-1215 
47 Munafo D, Hevener W, Crocker M, et al. A telehealth program for CPAP adherence reduces labor and yields similar adherence and efficacity when compared to standard of care. Sleep Breath 2016; 20: 777-785.

48 Frasnelli M, Baty F, Niedermann J, et al. Effect of telemetric monitoring in the first 30 days of continuous positive airway pressure adaptation for obstructive sleep apnoea syndrome - a controlled pilot study. $J$ Telemed Telecare 2016; 22: 209-214.

49 Hoet F, Libert W, Sanida C, et al. Telemonitoring in continuous positive airway pressure-treated patients improves delay to first intervention and early compliance: a randomized trial. Sleep Med 2017; 39: 77-83.

50 Turino C, de Batlle J, Woehrle $\mathrm{H}$, et al. Management of continuous positive airway pressure treatment compliance using telemonitoring in obstructive sleep apnoea. Eur Respir J 2017; 49: 1601128.

51 Parikh R, Touvelle MN, Wang H, et al. Sleep telemedicine: patient satisfaction and treatment adherence. Telemed J E Health 2011; 17: 609-614.

52 Murphie P, Little S, McKinstry B, et al. Remote consulting with telemonitoring of continuous positive airway pressure usage data for the routine review of people with obstructive sleep apnoea hypopnoea syndrome: a systematic review. J Telemed Telecare 2017; https://doi.org/10.1177/1357633X17735618.

53 Smith CE, Dauz ER, Clements F, et al. Telehealth services to improve nonadherence: a placebo-controlled study. Telemed J E Health 2006; 12: 289-296.

54 Hwang D, Chang JW, Benjafield AV, et al. Effects of telemedicine education and telemonitoring on continuous positive airway pressure adherence. The Tele-OSA Randomized Trial. Am J Respir Crit Care Med 2018; 197: $117-126$.

55 Stepnowsky C, Edwards C, Zamora T, et al. Patient perspective on use of an interactive website for sleep apnea. Int J Telemed Appl 2013; 2013: 239382.

56 Engelman H, Stitt C, Creswick L, et al. Effects on CPAP use of a patient support mobile app. Eur Respir J 2018; 52: Suppl. 62, PA2257.

57 Woehrle H, Arzt M, Graml A, et al. Effect of a patient engagement tool on positive airway pressure adherence: analysis of a German healthcare provider database. Sleep Med 2018; 41: 20-26.

58 Malhotra A, Crocker ME, Willes L, et al. Patient engagement using new technology to improve adherence to positive airway pressure therapy: a retrospective analysis. Chest 2018; 153: 843-850.

59 Mendelson M, Vivodtzev I, Tamisier R, et al. CPAP treatment supported by telemedicine does not improve blood pressure in high cardiovascular risk OSA patients: a randomized, controlled trial. Sleep 2014; 37: 1863-1870.

60 Randerath W, Bassetti CL, Bonsignore MR, et al. Challenges and perspectives in obstructive sleep apnoea: report by an ad hoc working group of the Sleep Disordered Breathing Group of the European Respiratory Society and the European Sleep Research Society. Eur Respir J 2018; 52: 1702616.

61 Cuthbertson A. Hackers steal dead people's medical records and sell them on the dark web. 2018, The independent. www.independent.co.uk/life-style/gadgets-and-tech/news/hackers-dead-people-medical-records-darkweb-cyber-security-data-a8444851.html Date last updated: 13 July 2018. Date last accessed: 30 September 2018.

62 Ministère des solidarités et de la santé. Décrets, arrêtés, circulaires. www.agir-telemedecine.org/wp-content/ uploads/2018/08/Convention-AM-Lib\%C3\%A9raux-et-t\%C3\%A91\%C3\%A9m\%C3\%A9decine.pdf Date last updated: 10 August 2018. Date last accessed: 30 September 2018.

63 Pelletier-Fleury N, Gagnadoux F, Philippe C, et al. A cost-minimization study of telemedicine. The case of telemonitored polysomnography to diagnose obstructive sleep apnea syndrome. Int J Technol Assess Health Care 2001; 17: 604-611.

64 Bros JS, Poulet C, Arnol N, et al. Acceptance of telemonitoring among patients with obstructive sleep apnea syndrome: how is the perceived interest by and for patients? Telemed J E Health 2018; 24: 351-359.

65 Miller AE. Telemedicine and the provider-patient relationship: what we know so far. http://nuffieldbioethics.org/ wp-content/uploads/Miller-E-2010-Evidence-review-Telemedicine-and-the-Provider-Patient-Relationship-what-weknow-so-far.pdf Date last updated: 17 January 2010. Date last accessed: 30 September 2018.

66 Kunisaki KM, Greer N, Khalil W, et al. Provider types and outcomes in obstructive sleep apnea case finding and treatment: a systematic review. Ann Intern Med 2018; 168: 195-202.

67 Parthasarathy S, Subramanian S, Quan SF. A multicenter prospective comparative effectiveness study of the effect of physician certification and center accreditation on patient-centered outcomes in obstructive sleep apnea. J Clin Sleep Med 2014; 10: 243-249.

68 Gasa M, Tamisier R, Launois SH, et al. Residual sleepiness in sleep apnea patients treated by continuous positive airway pressure. J Sleep Res 2013; 22: 389-397.

69 Bjornsdottir E, Janson C, Sigurdsson JF, et al. Symptoms of insomnia among patients with obstructive sleep apnea before and after two years of positive airway pressure treatment. Sleep 2013; 36: 1901-1909. 